\title{
Angiostrongylus cantonensis (Nematode: Metastrongyloidea) in molluscs from harbour areas in Brazil
}

\author{
Omar dos Santos Carvalho' ${ }^{1 /+}$, Ronaldo Guilherme Carvalho Scholte ${ }^{2,3}$, \\ Cristiane Lafeta Furtado de Mendonça ${ }^{1,4}$, Liana Konovaloff Jannotti Passos ${ }^{1}$, Roberta Lima Caldeira ${ }^{1}$ \\ ${ }^{1}$ Centro de Pesquisas René Rachou-Fiocruz, Belo Horizonte, MG, Brasil ${ }^{2}$ Swiss Tropical and Public Health Institute, Basel, Switzerland \\ ${ }^{3}$ University of Basel, Basel, Switzerland ${ }^{4}$ Pontifícia Universidade Católica de Minas Gerais, Belo Horizonte, MG, Brasil
}

Angiostrongylus cantonensis is the most common aetiological agent of human eosinophilic meningoencephalitis. Following a report indicating the presence of this parasite in Brazil in 2007, the present study was undertaken to investigate the presence of $\mathrm{A}$. cantonensis in the surrounding Brazilian port areas. In total, 30 ports were investigated and the following molluscs were identified: Achatina fulica, Belocaulus $s p$., Bradybaena similaris $s p$., Cyclodontina $s p$., Helix $s p$., Leptinaria $s p$., Melampus $s p$., Melanoides tuberculata, Phyllocaulis $s p$., Pomacea $s p$., Pseudoxychona $s p$., Rhinus $s p$., Sarasinula marginata, Streptaxis $s p$., Subulina octona, Succinea $s p$., Tomigerus $s p$., Wayampia $s p$. and specimens belonging to Limacidae and Orthalicinae. Digestion and sedimentation processes were performed and the sediments were examined. DNA was extracted from the obtained larvae and the internal transcribed spacer region 2 was analysed by polymerase chain reaction-restriction fragment length polymorphism after digestion with the endonuclease $\mathrm{ClaI}$. Of the 30 ports investigated in this study, 11 contained molluscs infected with $\mathrm{A}$. cantonensis larvae. The set of infected species consisted of S. octona, S. marginata, A. fulica and B. similaris. A total of 36.6\% of the investigated ports were positive for A. cantonensis, indicating a wide distribution of this worm. It remains uncertain when and how A. cantonensis was introduced into South America.

Key words: Angiostrongylus cantonensis - molluscs - eosinophilic meningoencephalitis - ports - Brazil

Two species of Metastrongylidae from the Angiostrongylus genus can affect humans: Angiostrongylus costaricensis (Morera \& Céspedes 1971), which is the aetiological agent of abdominal angiostrongyliasis in the Americas (Morera \& Céspedes 1971), and Angiostrongylus cantonensis (Chen 1935), which is the aetiological agent of eosinophilic meningoencephalitis (Alicata 1962) and occurs primarily in southeastern Asia and throughout the Pacific Basin (Alicata 1991).

A. cantonensis has been reported in Asia, Africa, Europe, Oceania, southeast Asia, North America and Central America (Wang et al. 2008). The first report of the occurrence of snails infected with $A$. cantonensis in South America was by Caldeira et al. (2007) and Pincay et al. (2009) later described the first human case in South America.

The cycle of A. cantonensis occurs mainly in molluscs and rodents. Molluscs become infected through the oral route or through percutaneous penetration by $\mathrm{L}_{1}$-stage larvae eliminated in the host's faeces. The parasite has no specific intermediate host and infects numerous species of terrestrial and aquatic molluscs (Malek \& Cheng 1974, Caldeira et al. 2007). Rodents can potentially acquire the parasite by eating infected molluscs and/or food contaminated with $\mathrm{L}_{3}$-stage larvae. After migration through the central nervous system, where two moults $\left(\mathrm{L}_{3}-\mathrm{L}_{4}-\mathrm{L}_{5}\right)$

+ Corresponding author: omar@cpqrr.fiocruz.br

Received 28 June 2011

Accepted 9 May 2012 take place, the adult worms migrate to their final habitat, the terminal branches of the pulmonary arteries. Humans are considered an accidental host because the migration of juvenile forms of the parasite is interrupted in the brain (meninges, medullar parenchyma and cerebellum) or rarely in the lungs and the worms do not reach the adult form, instead causing local inflammatory reactions.

As a result of the discovery of $A$. cantonensis in Brazil (Caldeira et al. 2007) and the hypothesis that the introduction of this parasite occurred through the migration of infected rodents on ships coming mainly from Asia and Africa, a project was implemented to investigate the presence of $A$. cantonensis in the areas surrounding the main ports of Brazil (Fig. 1). This project received financial support from the Ministry of Health of Brazil, which was coordinated by one of the authors (OSC).

The recorded presence of $A$. cantonensis larvae in Brazil is important because the parasite can cause clinical manifestations that can be confused with infectious meningitis of different aetiologies due to the transit of larvae through the meninges.

\section{MATERIALS AND METHODS}

Thirty Brazilian ports were investigated in 28 municipalities in 16 states (Table). All of the collection points were georeferenced. Molluscs were collected, packed and sent to the Laboratory of Medical Helminthology and Malacology at the René Rachou Institute-Oswaldo Cruz Foundation (Fiocruz) for examination. To verify the presence of $A$. cantonensis larvae, the molluscs were digested and the products were sedimented according to the protocol proposed by Wallace and Rosen (1969) and the Baermann-Moraes method (Moraes 1948). Molluscs 
of the same species and from the same location were pooled and then digested due to the large number of samples that were collected. After sedimentation, the material was analysed under a stereomicroscope for nematode larvae. The larvae from each collection point (pool) were submitted to molecular studies. DNA extraction was performed using the DNA Wizard Genomic Purification kit (Promega, Madison, USA) according to the manufacturer's instructions. The DNA was amplified to detect polymorphisms in internal transcribed spacer region 2 of the rRNA gene after restriction with $\mathrm{ClaI}$ endonuclease (polymerase chain reaction-restriction fragment length polymorphism) (Caldeira et al. 2003). A. cantonensis (Department of Parasitology, Medical School, Akita University, Japan) and A. costaricensis [Laboratory of Pathology, Instituto Oswaldo Cruz-Fiocruz, Rio de Janeiro (RJ), Brazil] were used as controls. Data management, visualisation and mapping was carried out in ArGIS version 9.3 (ESRI, Redlands, CA, USA).

\section{RESULTS}

A total of 6,095 mollusc specimens were collected: Achatina fulica (Bowdich, 1822) (Achatinidae), Belocaulus sp. Hoffmann, 1925 (Veronicellidae), Bradybaena similaris (Férussac, 1821) (Bradybaenidae), Bulimulus sp. Leach, 1814 (Bulimulidae), Cyclodontina sp. Beck, 1837 (Bulimulidae), Helix sp. Linné, 1758 (Helicidae), Leptinaria sp. Beck, 1837 (Subulinidae), Melampus coffeus (Linnaeus, 1758) (Ellobiidae), Melanoides tuberculatus (Muller, 1774) (Thiaridae), Phyllocaulis sp. Colosi, 1922 (Veronicellidae), Pomacea sp. Perry, 1811 (Ampulariidae), Pseudoxychona sp. Pilsbry, 1931 (Bulimulidae), Rhinus sp. Martens in Albers, 1860 (Bulimulidae), Sarasinula marginata (Semper, 1885) (Veronicel-

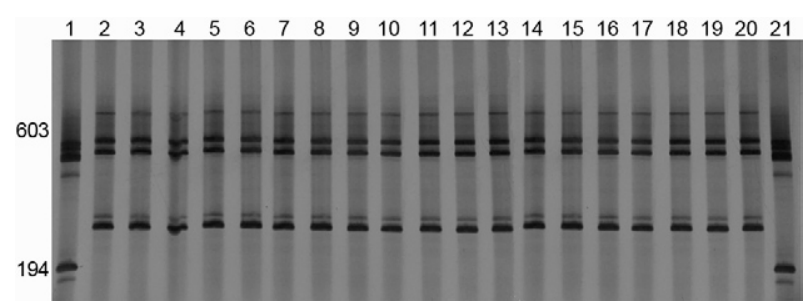

Fig. 1: silver-stained polyacrylamide gel $(6 \%)$ showing polymerase chain reaction-restriction fragment length polymorphism profiles for the internal transcribed spacer region 2 of rDNA digested with the ClaI enzyme. Lane 1: adult Angiostrongylus costaricensis worm [Rio de Janeiro, state of Rio de Janeiro (RJ)]; adult Angiostrongylus cantonensis worm (Akita/Japan); 3-7: L3 pool obtained from Subulina octona [Belém, state of Pará (PA), Recife, state of Pernambuco, Ilhéus, state of Bahia (BA), São Sebastião, state of São Paulo (SP), Santos (SP)]; 8-12: L3 pool obtained from Sarasinula marginata [Belém, Salvador (BA), Vila Velha, state of Espírito Santo, Niterói (RJ), Santos]; 13-16: L3 pool obtained from Achatina fulica [Ilhéus, Angra dos Reis (RJ), Paranaguá, state of Paraná, Navegantes, state of Santa Catarina (SC)]; 17-19: L3 pool obtained from Bradybaena similaris (Ilhéus, Navegantes, Santos); 20: adult $A$. cantonensis worm (Akita/Japan); 21: A. costaricensis worm (Rio de Janeiro). Molecular size markers are shown on the left. lidae), Streptaxis sp. Gray, 1837 (Streptaxidae), Subulina octona (Bruguière, 1792) (Subulinidae), Succinea sp. Draparnaud, 1801 (Succineidae), Tomigerus sp. Spix, 1827 (Bulimulidae), Wayampia sp. Tillier, 1980 (Systrophiidae) and specimens from the Orthalicinae (Bulimulidae) subfamily and the Limacidae family.

At $11(36.6 \%)$ of the 30 ports investigated, molluscs infected with larvae of $A$. cantonensis were found (Table). Fig. 1 shows the molecular profiles of these larvae (Lanes 3-19) compared with the profiles of A. cantonensis from Japan (Lanes 2, 20) and of A. costaricensis samples from Rio de Janeiro, RJ (Lanes 1, 21). A. cantonensis larvae were present in the following mollusc species: (i) S. octona (Belém, state of Pará, Recife, state of Pernambuco (PE), Ilhéus, state of Bahia (BA), São Sebastião and Santos, state of São Paulo (SP), (ii) S. marginata [Belém, Salvador (BA), Vila Velha, state of Espírito Santo (ES), Niterói (RJ), Santos], (iii) A. fulica [Ilhéus, Angra dos Reis (RJ), Paranaguá, state of Paraná, Navegantes, state of Santa Catariana (SC)] and (iv) B. similaris (Ilhéus, Navegantes, Santos). Fig. 2 shows the map with the locations of the 30 ports investigated.

\section{DISCUSSION}

The presence of $A$. cantonensis in Brazil was first suspected by Moll et al. (2006) at the V Congress of Infectology, at which a clinical case of eosinophilic meningoencephalitis in RJ that resulted in death 10 days after the ingestion of A. fulica was reported.

The results of the study that first identified A. cantonensis in Brazil (Caldeira et al. 2007) demonstrated the need for further studies. The parasite was found in two states in the Southeast Region, ES and SP. In ES, the parasite was found in the municipality of Cariacica, approximately $20 \mathrm{~km}$ towards the interior of the country on the margins of one of the main routes linking the coast to the centre of Brazil. The infected molluscs were B. similaris (100\% infection) S. octona (76\%), S. marginata (84\%) and A. fulica (66\%). Concurrently, A. cantonensis larvae were isolated and identified from the faeces of Rattus norvegicus collected in the peridomicile of patients from Cariacica, demonstrating the importance of this rodent in the lifecycle of the parasite. Experimental infection of $R$. norvegicus revealed that after 25 days of infection, several young adult worms were present in the meninges and after 57 days, male and female adult worms were found in the pulmonary arteries. In the city of São Vicente (SP), A. cantonensis larvae were found in A. fulica (Caldeira et al. 2007).

In Ecuador, Pincay et al. (2009) reported 26 cases of eosinophilic meningoencephalitis and several of these patients were reported to have consumed raw molluscs prepared as a ceviche. One of the patients died and the autopsy results revealed the presence of A. cantonensis larvae in the subarachnoid space. This is the first report of a human infection proven by parasitology in South America. Molluscs and two rodents (R. norvegicus and Rattus rattus) harbouring adult $A$. cantonensis worms were collected. After the first report of A. cantonensis in Brazil by Caldeira et al. (2007), several other authors described the presence of $A$. cantonensis in this country. In Olinda 


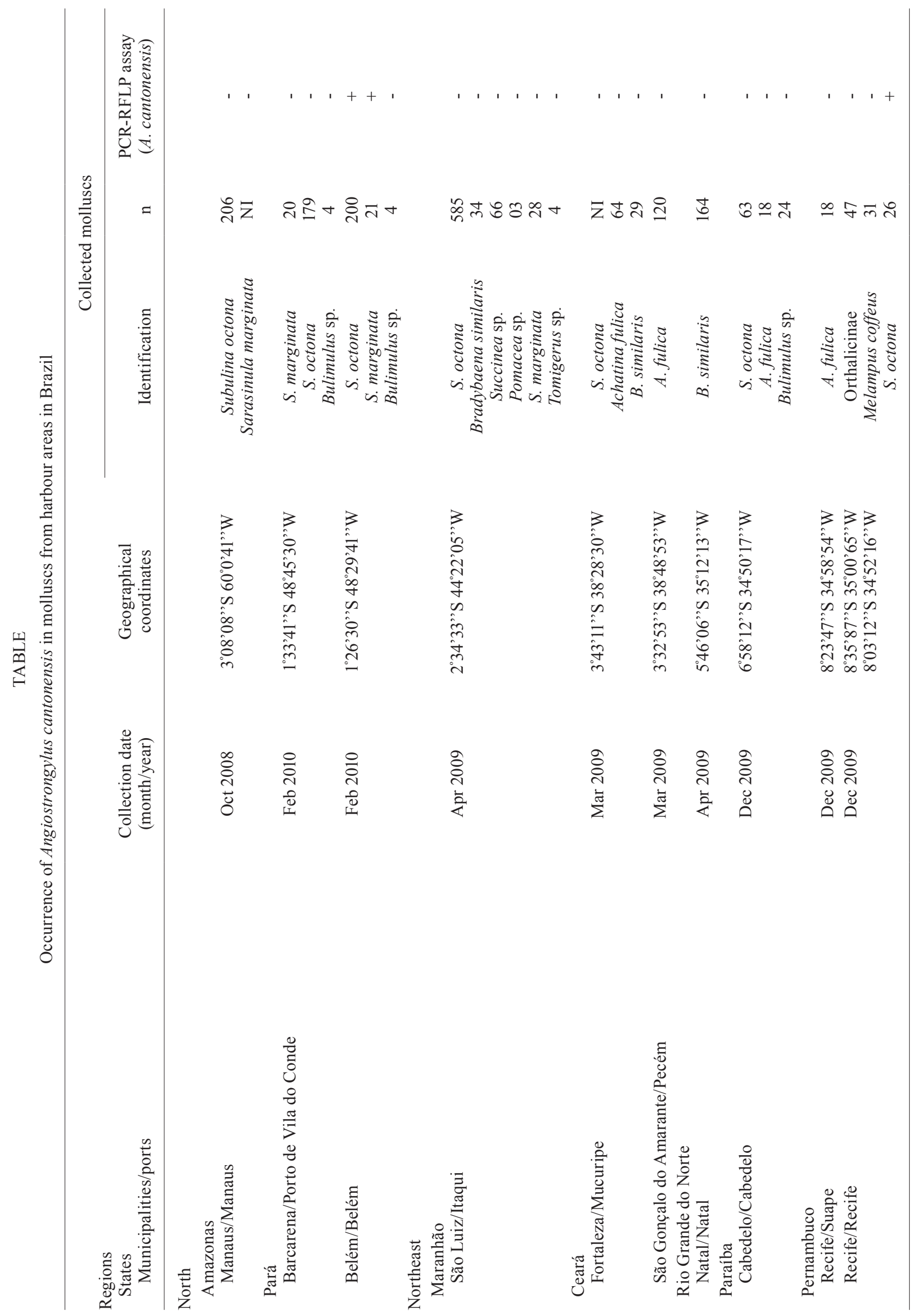




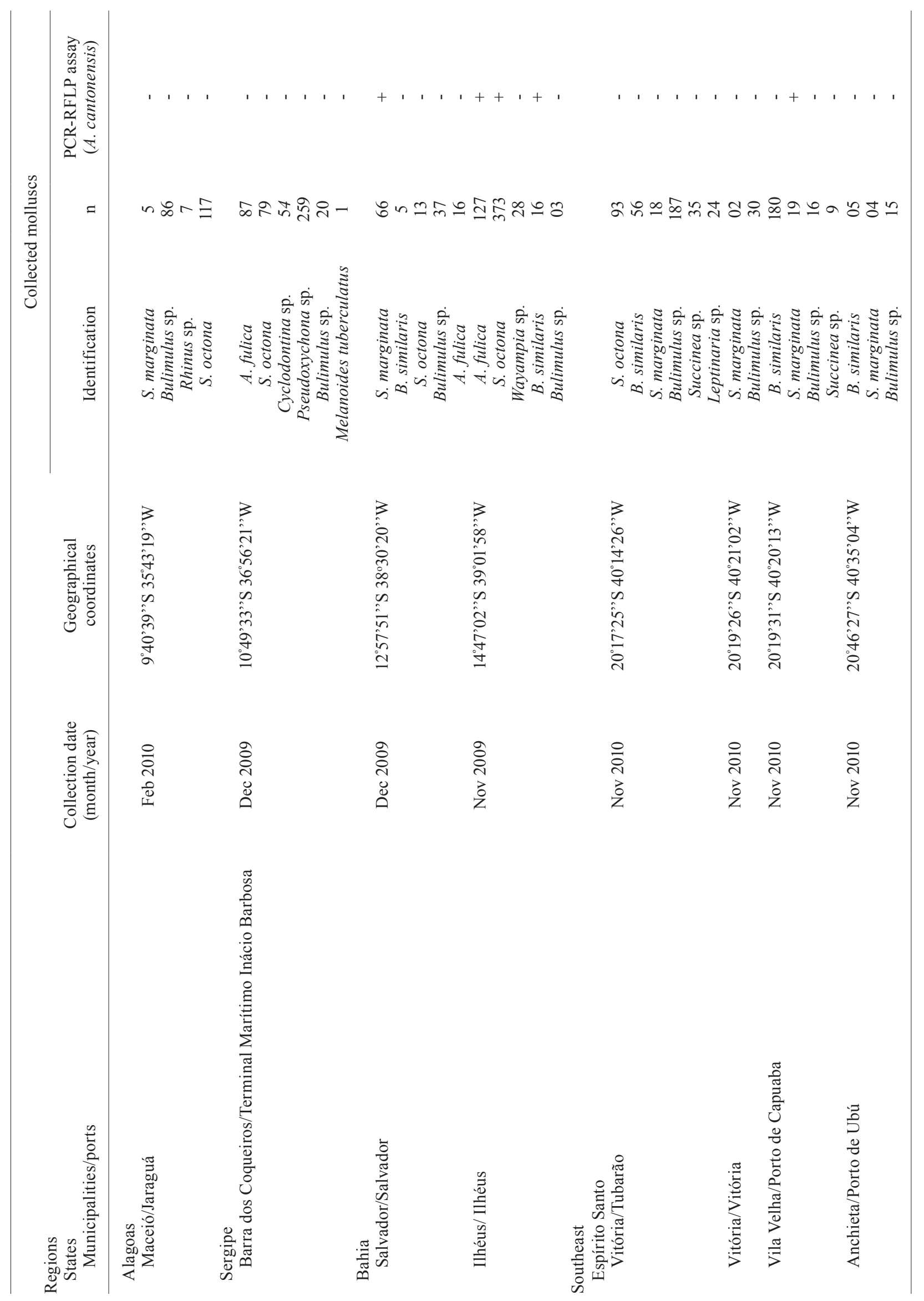




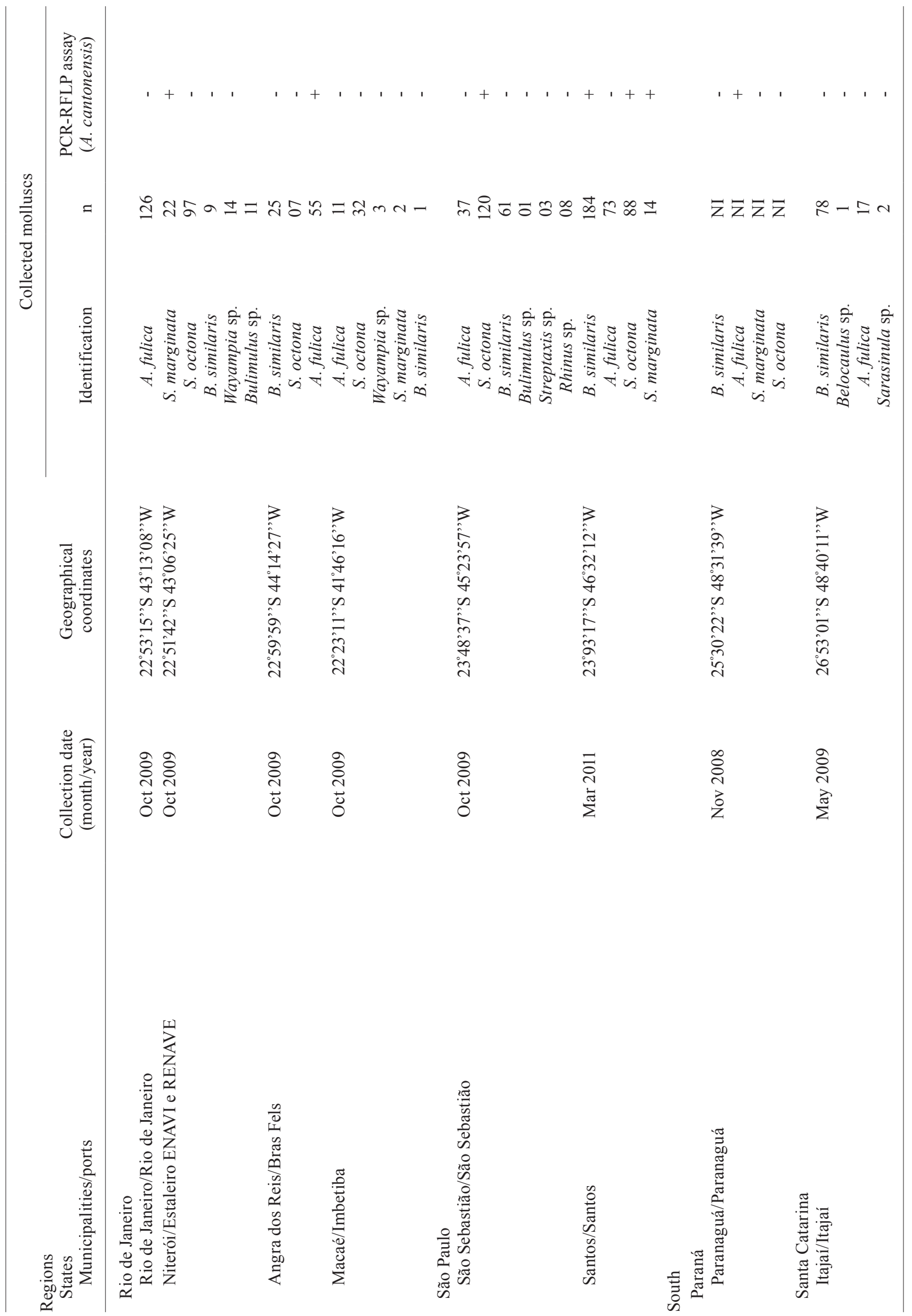




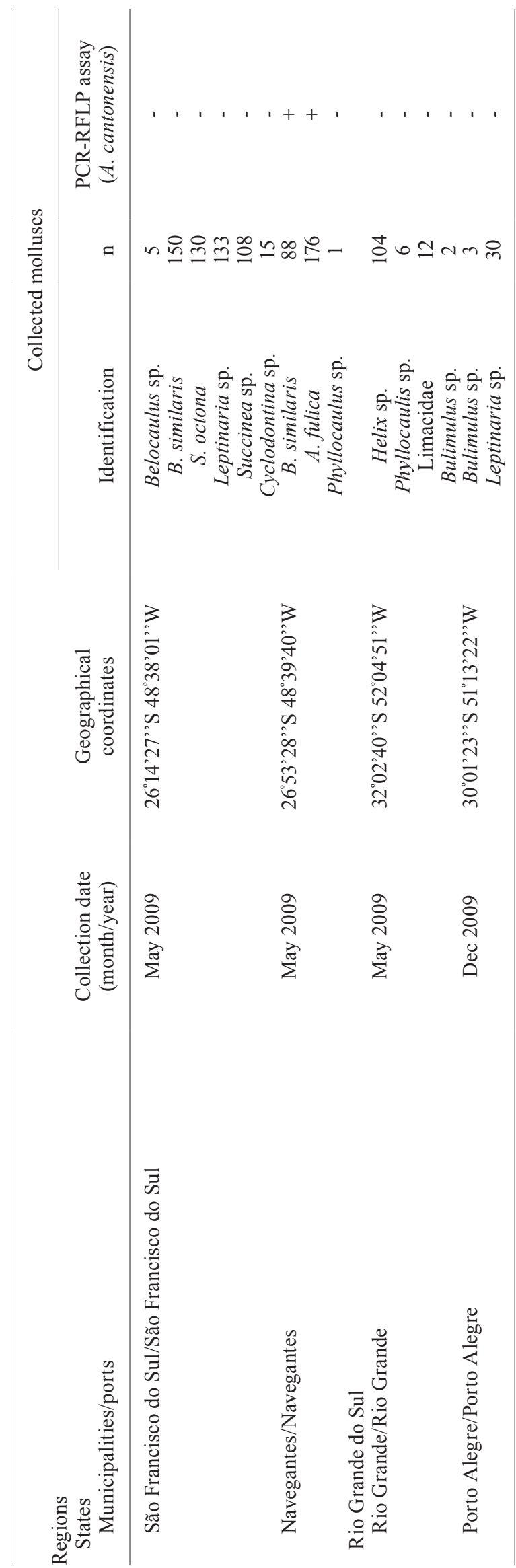

(PE), Lima et al. (2009) described a clinically identified case with neurological impairment due to $A$. cantonensis. Thiengo et al. (2010) reported A. cantonensis larvae parasitizing A. fulica that had originated from a municipality in Escada (PE). Maldonado Junior et al. (2010) reported the presence of this nematode in the municipalities of Barra do Pirai, São Gonçalo (RJ) and Joinville (SC).

The results presented in this study confirm the nonspecificity of $A$. cantonensis in relation to the intermedi-

A

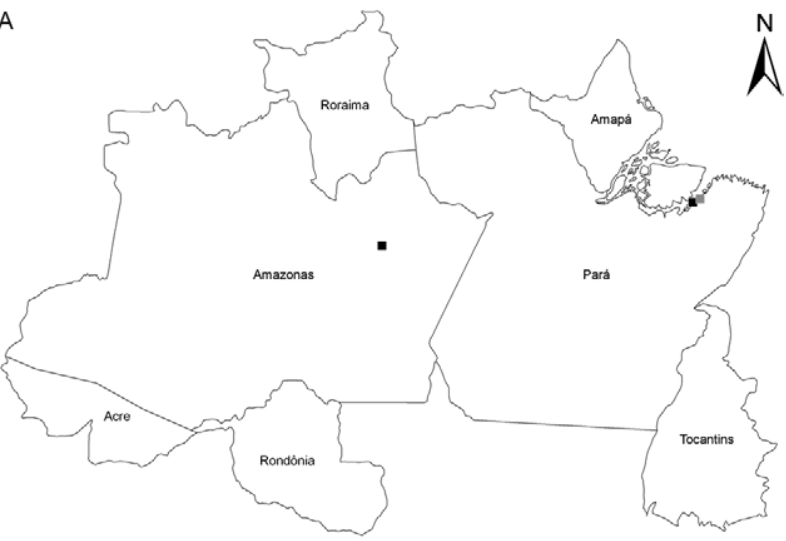

Ports investigated

- molluscs positive

$B$
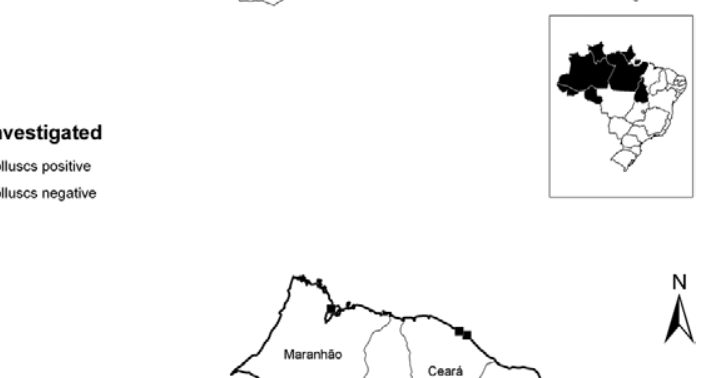

\section{Ports investigated}

" molluscs positive

molluscs negative

Fig. 2: geographical location of 30 ports of Brazil where molluscs were found not infected and infected with Angiostrongylus cantonensis. A: North Region of Brazil showing the location of three ports investigated; B: Northeast, Southeast and South Regions of Brazil showing the location of 27 ports investigated. 
ate host because the parasite was found in a variety of gastropods, including S. octona, S. marginata, A. fulica and $B$. similaris. These molluscs have been shown to be hosts of A. cantonensis in South America in studies by Caldeira et al. (2007), Pincay et al. (2009), Maldonado Junior et al. (2010) and Thiengo et al. (2010).

The molecular diagnostic method utilised in this study was shown to be accurate, cost-effective and quick and therefore the use of this method would enable immediate responses to be obtained during outbreaks. In contrast to the molecular diagnostic method, the parasitological method requires approximately 30 days to obtain the adult forms for morphological identification and must be performed by an expert taxonomist, making this method cumbersome.

When and how the introduction of $A$. cantonensis in South America occurred remains unknown. There is, however, a concordance that the introduction occurred through the migration of infected rodents on ships travelling from other continents, especially Africa and Asia (Caldeira et al. 2007, Pincay et al. 2009, Maldonado Junior et al. 2010).

Future studies are needed to investigate the prevalence of molluscs parasitized by $A$. cantonensis in the interior regions to map the distribution and migration route of this parasite.

\section{ACKNOWLEDGEMENTS}

To the State Secretariat of Health of investigated states and SUCEN (SP), for laboratory support and the vehicle used in the collection of molluscs, to the technicians Gisele Espíndola, Tatiana Maria Teodoro and José Geraldo Amorim, and the students from the Helminthology and Malacology Medical Laboratory of $\mathrm{CPqRR}$, for technical support.

\section{REFERENCES}

Alicata JE 1962. Angiostrongylus cantonensis (Nematoda: Metastrongylidae) as a causative agent of eosinophilic meningits of man in Hawaii and Tahiti. Can J Zool 40: 5.

Alicata JE 1991. The discovery of Angiostrongylus cantonensis as a cause of human eosinophilic meningitis. Parasitol Today 7: 151-153.
Caldeira RL, Carvalho OS, Mendonça CLFG, Graeff-Teixeira C, Silva MCF, Ben R, Maurer R, Lima WS, Lenzi HL 2003. Molecular differentiation of Angiostrongylus costaricensis, A. cantonensis and $A$. vasorum by polymerase chain reaction-restriction fragment length polymorphism. Mem Inst Oswaldo Cruz 98: 1039-1043.

Caldeira RL, Mendonça CLGF, Goveia CO, Lenzi HL, Graeff-Teixeira C, Lima WS, Mota EM, Pecora IL, de Medeiros AMZ, Carvalho OS 2007. First record of molluscs naturally infected with Angiostrongylus cantonensis (Chen, 1935) (Nematoda: Metastrongylidae) in Brazil. Mem Inst Oswaldo Cruz 102: 887-889.

Lima ARMC, Mesquita SD, Santos SS, Aquino ERP, Rosa LRS, Duarte FS, Teixeira AO, Costa ZRS, Ferreira MLB 2009. Alicata disease. Neuroinfestation by Angiostrongylus cantonensis in Recife, Pernambuco. Brazil. Arq Neuropsiquiatr 67: 1093-1096.

Maldonado Júnior A, Simões RO, Oliveira APM, Motta EM, Fernandez MA, Pereira ZM, Monteiro SS, Torres EJL, Thiengo SC 2010. First report of Angiostrongylus cantonensis (Nematoda: Metastrongylidae) in Achatina fulica (Mollusca: Gastropoda) from Southeast and South Brazil. Mem Inst Oswaldo Cruz 105: 938-941.

Malek EA, Cheng TC 1974. Medical and economic malacology, Academic Press, New York, 398 pp.

Moll A, Zanini G, Graeff-Teixeira C, Brasil P 2006. Primeiro caso de meningite eosionofílica por Angiostrongylus cantonensis no Brasil. In V Congresso Paulista de Infectologia, Resumo ID:CI.20.

Moraes RG 1948. Contribuição para o estudo do Strongyyloides stercoralis e da estrongiloidose no Brasil. Rev Ser Saude Publica 1: 507-624.

Morera P, Céspedes R 1971. Angiostrongilosis abdominal. Una nueva parasitosis humana. Acta Med Costarric 14: 159-173.

Pincay T, Garcia L, Decker O, Martini L, Moreira JM 2009. Angiostrongiliasis por Parastrongylus (Angiostrongylus) cantonensis em Ecuador. Bol Epidem Ecuador 6: 25-32.

Thiengo SC, Maldonado A, Mota EM, Torres EJL, Caldeira RL, Carvalho OS, Oliveira APM, Simões RO, Fernandez MA, Lanfredi RM 2010. The giant African snail Achatina fulica as natural intermediate host of Angiostrongylus cantonensis in Pernambuco, Northeast Brazil. Acta Trop 115: 194-199.

Wallace GD, Rosen L 1969. Techniques for recovering and identifying larvae of Angiostrongylus cantonensis from molluscs. Malacol 7: 427-438.

Wang QP, Lai DH, Zhu XQ, Chen XG, Lun ZR 2008. Human angiostrongyliasis. Lancet Infect Dis 8: 621-630. 